Article

\title{
New Framework for Quality Function Deployment Using Linguistic Z-Numbers
}

\author{
Chao Song ${ }^{1}$, Jian-Qiang Wang ${ }^{1}$ and Jun-Bo $\mathrm{Li}^{2, *}$ \\ 1 School of Business, Central South University, Changsha 410012, China; 171613565@csu.edu.cn (C.S.); \\ jqwang@csu.edu.cn (J.-Q.W.) \\ 2 Business School, Guilin University of Technology, Guilin 541004, China \\ * Correspondence: junboli@glut.edu.cn
}

Received: 24 December 2019; Accepted: 6 February 2020; Published: 10 February 2020

\begin{abstract}
Quality function deployment (QFD) is a useful design quality control tool in service enterprises and manufacturing enterprises. However, there are several issues in extant QFD frameworks, that is, in three aspects: description of evaluation information, weight determination of expert team members (TMs), and weight identification of customer requirements (CRs). In order to address these issues, a novel QFD framework is first proposed utilizing linguistic Z-numbers (LZNs) with integrated subjective and objective weights of TMs and CRs. The LZNs can represent uncertain information and the reliability of information in a specific way while the fuzzy numbers cannot. Moreover, the order relation analysis (G1) method and improved maximum consensus (MC) method are developed to get the subjective and objective weights of TMs, respectively. Further, the step-wise weight assessment ratio analysis (SWARA) method and statistical distance (SD) method are studied to acquire combined weights of CRs. Next, the proposed QFD framework is applied to a case of logistics service provider, which illustrates the availability and utility of the framework. Then, a sensitivity analysis is conducted to prove the reliability of the framework. Finally, two comparative analyses are performed to declare the advantages of the framework. Results indicate the proposed QFD framework is better than existing models.
\end{abstract}

Keywords: quality function deployment; multi-criteria decision-making; linguistic Z-numbers; combined weights; improved maximum consensus method

\section{Introduction}

As one of the most famous design quality control technologies, quality function deployment (QFD) [1] is an effective and efficient way to convert customer requirements into production demand [2]. This facilitates research and development $(\mathrm{R} \& \mathrm{D})$ companies to design and manufacture customer-driven products. Generally speaking, there are four phases in classical QFD models, including product overall design phase, part design phase, process design phase, and production system design phase [3]. In these phases, customer requirements are translated into engineering characteristics, part characteristics, process plans, and production requirements, respectively [4]. Further, a matrix is required in each phase to construct these relationships which is called as house of quality (HOQ).

The HOQ in the first phase is the most fundamental and central one [5] which is illustrated in Figure 1. In particular, the seven components of HOQ are customer requirements (CRs), engineering characteristics (ECs), relationship between CRs and ECs, importance of CRs, importance of ECs, correlation among ECs, and benchmarking analysis [4]. As far as we know, numerous researchers have integrated QFD models with multi-criteria decision-making (MCDM) theories to rank the ECs [6,7]. However, although the usefulness of QFD models has improved a little, three deficiencies still exist in these studies which are formulated below: (1) the evaluation information of relationships between 
CRs and ECs was given with crisp values or various kinds of fuzzy numbers [8]. Nevertheless, in most actual circumstances, the information provided by experts may be unreliable or a bit reliable because of their lacks of professional knowledge and limited time to make decisions; (2) as a rule, the ranking process of ECs requires several QFD experts to participate in the consultations. However, the weights of expert team members (TMs) were provided directly without any discussions [2], which was not scientific and rational. What's more, it was inconsistent with actuality to determine the experts' weights by an either subjective or objective method [9]; (3) the ranking results may be inaccurate in real-life decision-making processes when only subjective or objective weighting method employed [10,11].
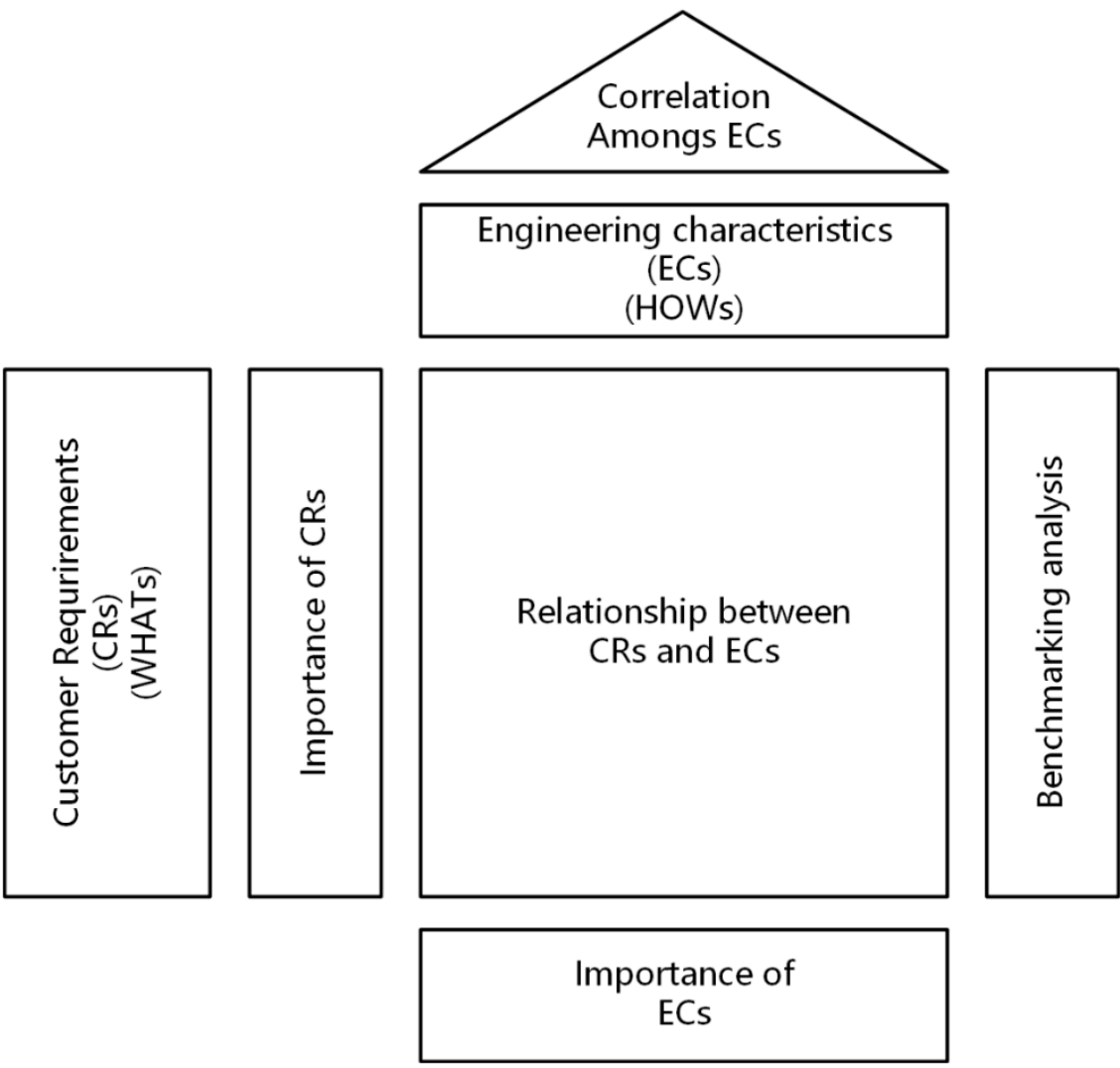

Figure 1. The house of quality (HOQ).

To address the above mentioned deficiencies, a new framework is essential for QFD models. At that point, the motivations of this paper are itemized as follows:

(1) Considering the fuzzy information and reliability of this information at the same time, Z-numbers are suitable tools to describe the evaluation values $[12,13]$. Nonetheless, the operations of Z-numbers are complex [14,15]. Meanwhile, the processing of Z-numbers into various fuzzy numbers may lose the original information. Therefore, in this paper, linguistic Z-numbers (LZNs) [16,17] are utilized to represent the evaluation information.

(2) To dispose the improper ways to determine the weights of TMs with single preference, the proposed QFD model takes the subjective and objective weights into considerations. Since order relation analysis (G1) method [18] and maximum consensus (MC) method [19] are practical means to identify the subjective and objective weights, separately. Further, MC method is improved due to the issue that it merely thinks over the positive ideal point. Thus, the G1 method and improved MC method are developed to obtain combined weights of TMs.

(3) In order to fill the research gap about the combined weights of TMs, SWARA method [20] and extended statistical distance (SD) method [21] are mixed to acquire the hybrid weights of CRs. 
This paper aims to propose a novel framework for QFD using LZNs with integrated weights of TMs and CRs. This framework contains three stages. The first stage is to construct the decision matrix, the second is to determine the combined weights of TMs and CRs, and the third is to rank ECs in terms of their importance. In sum, the contributions of this study are listed below:

(1) The novel framework for QFD is set up. The sensitivity analysis and comparative analyses indicate the reliabilities, effectiveness, and practicality of the proposed QFD model. Namely, the proposed QFD framework is superior to existing QFD models.

(2) LZNs are absorbed to express the evaluation information, which involves the fuzzy information and the reliability of fuzzy information simultaneously.

(3) The G1 method and improved MC method are utilized to get the combined weights of experts. And SWARA method and extended SD method are used to gain the combined weights of CRs. These methods are appropriate for QFD to be applied in real life.

(4) The MC approach is improved by considering both the positive and negative ideal points. The weights derived by improved MC method may be more precise than traditional MC method.

(5) The technique for order performance by similarity to ideal solution (TOPSIS) method is extended with LZNs which enriches the theories of LZNs.

The rest of this study is established in the following order. In Section 2, the literatures about QFD models are reviews. Section 3 introduces the definitions of Z-numbers and linguistic terms sets. Moreover, the relevant theories of LZNs are presented. In Section 4, the concrete QFD framework is proposed. Section 5 implements the proposed QFD framework in a case to verify the availability and validity of it. Finally, the conclusions are drawn in Section 6.

\section{Literature Review}

With the development of the social economy and enlarged volume of information, the application of multiple criteria decision-making (MCDM) has become increasingly wide. Many popular and topical MCDM methods have been proposed by researchers, such as: SAW (simple additive weighting method), AHP (analytic hierarchy process) [22], TOPSIS (technique for order of preference by similarity to ideal solution) [23], ELECTRE (elimination and choice expressing reality) [24], VIKOR (VlseKriterijumska Optimizacija I Kompromisno Resenje) [25], PROMETHEE (preference ranking organization method for enrichment evaluations) [26], GDM (grey decision-making) [27], SWARA [20], and BWM [28].

The QFD model, integrating with fuzzy theories and MCDM methods, has been widely investigated by many scholars [29]. For instance, analytical network process (ANP) and fuzzy logic were utilized to structure the intensive QFD framework by Zaim et al. [30]. Abdel-Basset, Manogaran [31] presented a QFD method where analytical hierarchy process (AHP) was adopted to determine the weights of CRs. Hsu et al. [29] developed a new QFD approach with fuzzy Delphi method. Wu et al. [32] proposed a two-phase robust fuzzy QFD procedure to assess the service station for nail catering service. Wu et al. [3] provided a hybrid QFD model with decision-making trial and evaluation laboratory (DEMATEL) technique and VIKOR method within hesitant fuzzy environment. In addition, the fuzzy QFD-MCDM frameworks were applied to various fields, such as supply chain management strategies formulation problems [2,33], risk management of hazardous material transportation process [34], and green supplier selection problems [6].

However, as indicated above, the ways to determine weights of QFD experts and customer requirements were inaccurate in extant studies. That is, the weights of experts and CRs were either supposed to be known completely or calculated by only one type of approach: subjective approach or objective approach. To be specific, in subjective weight estimation methods, the weights information is obtained based on humans' subjective judgments or experience $[35,36]$. In contrast with the subjective methods, the objective weights are derived merely by the data given in the decision matrices [37,38]. Therefore, it may cause the intense subjectivity or the absence of subjective preference if only the subjective method or objective method is used in weights determination. 
There was an issue in the information representation of extant fuzzy QFD-MCDM models, i.e., the models cannot reserve the irresponsible evaluation integrally. Hence, Z-numbers are the pretty helpful instruments to denote this information [12]. Two ways were investigated to handle Z-numbers. One is to dispose Z-numbers straightforward with the operations of them [15]. However, Wang et al. [16] pointed out that the operations are too intricate to be employed in common life. The other is to transform Z-numbers into other forms of fuzzy numbers. Nevertheless, Wang et al. [16] indicated that this way may lead to information distortion. As a result, Wang et al. [16] defined the linguistic Z-numbers (LZNs) to cover these problems.

In this paper, the evaluation information of relationships between CRs and ECs is depicted by LZNs so that the information can be kept perfectly. What's more, both subjective and objective methods are proposed to derive the combined weights of QFD experts and CRs. The outcomes show that the proposed QFD framework outperforms state-of -the-art QFD methods.

\section{Preliminaries}

In this section, we review some basic notions related to linguistic Z-numbers and the operational law, distance, and comparison method of linguistic Z-numbers are introduced. Since linguistic Z-numbers can be an integrated formation of Z-numbers and linguistic terms sets [16], we briefly present the definitions of $Z$-numbers and linguistic terms sets.

Definition 1 ([12]). Let $\boldsymbol{X}$ be a real-valued uncertain variable. A Z-number $(\boldsymbol{A}, \boldsymbol{B})$ is an ordered pair of fuzzy numbers which is related to $\boldsymbol{X}$, where $\boldsymbol{A}$ is a fuzzy restriction on the values that $\boldsymbol{X}$ is allowed to take, and $\mathbf{B}$ is $a$ reliability measure of $A$.

In general, the two components $\mathbf{A}$ and $\mathbf{B}$ are described in nature languages. For example, the Z-number $(\mathbf{A}, \mathbf{B})=$ (about 45 million, quite sure) can be used to evaluate the population of Spain (X).

Definition 2 ([39]). Let $S=\left\{s_{a} \mid a=0,1, \ldots, 2 t\right\}$ be a finite ordered discrete term set, where $S_{a}$ represents a possible value for a linguistic variable. We require that $s_{a}$ and $s_{b}$ satisfy the following conditions:

(1) The set $S$ is ordered: $\boldsymbol{s}_{\boldsymbol{a}}>\boldsymbol{s}_{\boldsymbol{b}}$ if and only if $\boldsymbol{a}>\boldsymbol{b}$;

(2) Negation operator: $n e g\left(s_{a}\right)=s_{2 t-a}$.

Definition 3 ([16]). Let $X$ be a universe of discourse, $S_{1}=\left\{s_{0}, s_{1}, \ldots, s_{2 p}\right\}$ and $S_{2}=\left\{s_{0^{\prime}}^{\prime}, s_{1}^{\prime}, \ldots, s_{2 q}^{\prime}\right\}$ be two linguistic term sets. A linguistic Z-number set (LZNS) in $X$ is composed of the fuzzy restriction $A(x)$ and the reliability measure $\boldsymbol{B}(\boldsymbol{x})$, where $\boldsymbol{A}(\boldsymbol{x}) \in S_{\mathbf{1}}$ and $\boldsymbol{B}(\boldsymbol{x}) \in S_{2}$. Then, a LZNS can be defined as follows:

$$
Z=\{\langle x, A(x), B(x)\rangle \mid x \in X\}
$$

It should be noted that two LTSs, $S_{1}$ and $S_{2}$, denote different linguistic preference information, separately. In particular, a LZNS is regarded as a linguistic Z-number (LZN) when $X$ has only one element which is illustrated by $Z=\langle x, A(x), B(x)\rangle$. In order to facilitate the representation, a LZN can be also denoted by $Z=\langle A, B\rangle$, where $A$ and $B$ are linguistic terms, respectively.

Definition 4 ([40]). Let $S=\left\{s_{i} \mid i=0,1, \ldots, 2 t\right\}$ be a linguistic term set, and $\boldsymbol{\theta}_{i}$ is a numeric value ranging from 0 to 1. The linguistic scale function (LSF) conducts the mapping from $s_{i}$ to $\boldsymbol{\theta}_{i}$ which is defined below:

$$
f: s_{i} \rightarrow \theta_{i}(i=0,1, \ldots, 2 t)
$$


where $0 \leq \theta_{1} \leq \theta_{2} \leq \ldots \leq \theta_{2 t} \leq 1$. A LSF is a strictly monotonically increasing function regarding to label $i$. Simultaneously, symbol $\theta_{i}$ expresses the preference information of decision-makers (DMs) when linguistic term $s_{i}$ is used. Thus, LSF represents the semantics of $s_{i}$. There are three types of LSFs are shown as follows:

(1) The first LSF is defined in terms of subscript function $s u b\left(s_{i}\right)=i$. Further, the appraisement scale for linguistic term is even.

$$
f_{1}\left(s_{i}\right)=\theta_{i}=\frac{i}{2 t}(i=0,1, \ldots, 2 t)
$$

(2) The second LSF is developed according to the exponential scale. Moreover, from the middle of given linguistic term to both ends, the absolute deviation between adjacent linguistic terms increases.

$$
f_{2}\left(s_{i}\right)=\theta_{i}=\left\{\begin{array}{l}
\frac{\gamma^{t}-\gamma^{t-i}}{2 \gamma^{t}-2}(i=0,1, \ldots, t) \\
\frac{\gamma^{t}+\gamma^{i-t}-2}{2 \gamma^{t}-2}(i=t+1, t+2, \ldots, 2 t)
\end{array}\right.
$$

As we can see in Equation (4), there is a parameter $\gamma$ which can be identified by experts' advice or subjective approach. On the basis of lots of experiment researches, Bao, Lian [41] explained that the value $\gamma$ usually is derived in the interval $[1.36,1.4]$.

(3) The third LSF is proposed based on prospect theory's value function. Prospect theory [42], is a very successful descriptive model about decision making under risk. This theory acknowledges value gains and losses differently, placing more weight on perceived gains versus perceived losses. This theory is more consistent with the practical decision, and it can explain a lot of things that the expected utility theory can't. From the middle of given linguistic term to both ends, the absolute deviation between adjacent linguistic terms decreases.

$$
f_{3}\left(s_{i}\right)=\theta_{i}=\left\{\begin{array}{l}
\frac{t^{\alpha}-(t-i)^{\alpha}}{2 t^{\alpha}}(i=0,1, \ldots, t) \\
\frac{t^{\beta}+(i-t)^{\beta}}{2 t^{\beta}}(i=t+1, t+2, \ldots, 2 t)
\end{array}\right.
$$

where $\alpha, \beta \in 0,1$ are the concavo-convex degree of the subjective value function in the area of the gain and loss, respectively. On the basis of empirical data, Kahneman and Tversky [42] gave $\alpha=\beta=0.88$.

For information integrity and calculation convenience in the process of decision-making, these three aforementioned functions are supposed to be continuous, that is, $f^{*}: s_{i} \rightarrow \theta_{i}(0 \leq i \leq 2 t)$. Further, the inverse function of $f^{*}$ is marked as $f^{*-1}$.

There are also some LSFs based on other distances could be considered, such as fuzzy divergence [43] and fuzzy similarity [44].

In this study, we assume $\gamma=1.4, \alpha=\beta=0.88$, and the characteristics of three LSFs are displayed in Figure 2.

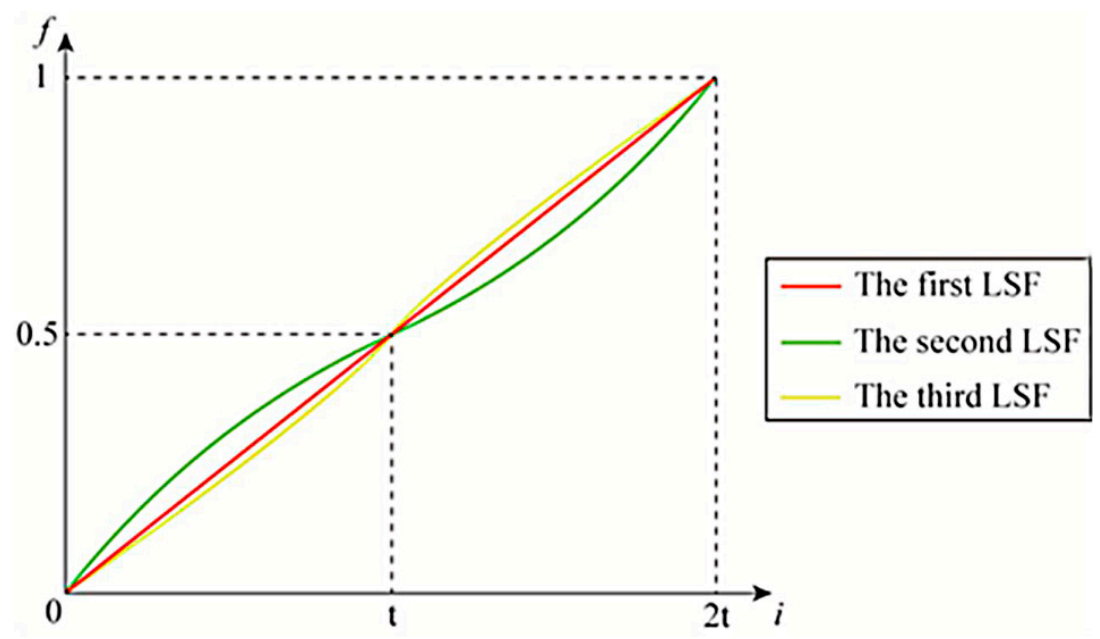

Figure 2. Graphical representation of three LSFs. 
Definition 5 ([16]). Let $z_{i}=\left(A_{i}, B_{i}\right)$ and $z_{j}=\left(A_{j}, B_{j}\right)$ be two LZNs, and $f^{*}$ and $g^{*}$ be one of three LSFs denoted by Equations (1) and (2), separately. The operational laws of LZNs are defined as follows:

(1) $n e g\left(z_{i}\right)=\left(f^{*-1}\left(f^{*}\left(A_{2 p}\right)-f^{*}\left(A_{i}\right)\right), g^{*-1}\left(g^{*}\left(B_{2 q}\right)-g^{*}\left(B_{i}\right)\right)\right)$;

(2) $z_{i} \oplus z_{j}=\left(f^{*-1}\left(f^{*}\left(A_{i}\right)+f^{*}\left(A_{j}\right)\right), g^{*-1}\left(\frac{f^{*}\left(A_{i}\right) \times g^{*}\left(B_{i}\right)+f^{*}\left(A_{j}\right) \times g^{*}\left(B_{j}\right)}{f^{*}\left(A_{i}\right)+f^{*}\left(A_{j}\right)}\right)\right)$;

(3) $z_{i} \otimes z_{j}=\left(f^{*-1}\left(f^{*}\left(A_{i}\right) f^{*}\left(A_{j}\right)\right), g^{*-1}\left(g^{*}\left(B_{i}\right) g^{*}\left(B_{j}\right)\right)\right)$;

(4) $\lambda z_{i}=\left(f^{*-1}\left(\lambda f^{*}\left(A_{i}\right)\right), B_{i}\right)$, where $\lambda \geq 0$;

(5) $z_{i}^{\lambda}=\left(f^{*-1}\left(f^{*}\left(A_{i}\right)^{\lambda}\right), g^{*-1}\left(g^{*}\left(B_{i}\right)^{\lambda}\right)\right)$, where $\lambda \geq 0$.

Definition 6 ([16]). Let $z_{i}=\left(A_{i}, B_{i}\right)$ and $z_{j}=\left(A_{j}, B_{j}\right)$ be two LZNs, the score function of $z_{i}$ is defined below:

$$
\operatorname{SF}\left(z_{i}\right)=f^{*}\left(A_{i}\right) \times g^{*}\left(B_{i}\right)
$$

The accuracy function of $z_{i}$ is defined as follows:

$$
A F\left(z_{i}\right)=f^{*}\left(A_{i}\right) \times\left(1-g^{*}\left(B_{i}\right)\right)
$$

Therefore, the comparison approach can be proposed by the following rules:

(1) If $A_{i}>A_{j}$ and $B_{i}>B_{j}$, then $z_{i}$ is strictly superior than $z_{j}$, denoted by $z_{i}>z_{j}$;

(2) If $S F\left(z_{i}\right)>S F\left(z_{j}\right)$ or $S F\left(z_{i}\right)=S F\left(z_{j}\right)$ and $A F\left(z_{i}\right)>A F\left(z_{j}\right)$, then $z_{i}$ is superior than $z_{j}$, denoted by $z_{i}>z_{j}$.

(3) If $S F\left(z_{i}\right)=S F\left(z_{j}\right)$ and $A F\left(z_{i}\right)=A F\left(z_{j}\right)$, then $z_{i}$ is equal to $z_{j}$, denoted by $z_{i} \sim z_{j}$.

(4) If $S F\left(z_{i}\right)=S F\left(z_{j}\right)$ and $A F\left(z_{i}\right)<A F\left(z_{j}\right)$ or $S F\left(z_{i}\right)<S F\left(z_{j}\right)$, then $z_{i}$ is inferior than $z_{j}$, denoted by $z_{i}<z_{j}$.

Definition 7 ([16]). Let $z_{i}=\left(A_{i}, B_{i}\right)$ and $z_{j}=\left(A_{j}, B_{j}\right)$ be two LZNs, and $f^{*}$ and $g^{*}$ be two LSFs. The distance between $z_{i}$ and $z_{j}$ is defined as follows:

$$
\begin{aligned}
d\left(z_{i}, z_{j}\right) & =\frac{1}{2}\left(\left|f^{*}\left(A_{i}\right) \times g^{*}\left(B_{i}\right)-f^{*}\left(A_{j}\right) \times g^{*}\left(B_{j}\right)\right|\right. \\
& \left.+\max \left\{\left|f^{*}\left(A_{i}\right)-f^{*}\left(A_{j}\right)\right|,\left|g^{*}\left(B_{i}\right)-g^{*}\left(B_{j}\right)\right|\right\}\right) .
\end{aligned}
$$

\section{The Proposed Model for QFD}

This section develops a hybrid decision-making model to obtain the importance degrees of engineering characteristics (ECs). In this model, both subjective and objective weights are considered for QFD team members (TMs) and customer requirements (CRs) at the same time. There are three stages included in the proposed model. The first stage is to determine the subjective weights of QFD experts TMs by order relation analysis (G1) method and objective weights of TMs by improved maximum consensus (MC) method, and the second stage is to estimate the subjective weights of CRs by SWARA method and objective weights of CRs by statistical distance (SD) method. In addition, the last stage is to prioritize the ECs according to the importance ratings of them. For convenience, Figure 3 is provided to visualize the decision-making procedures in the developed model. 


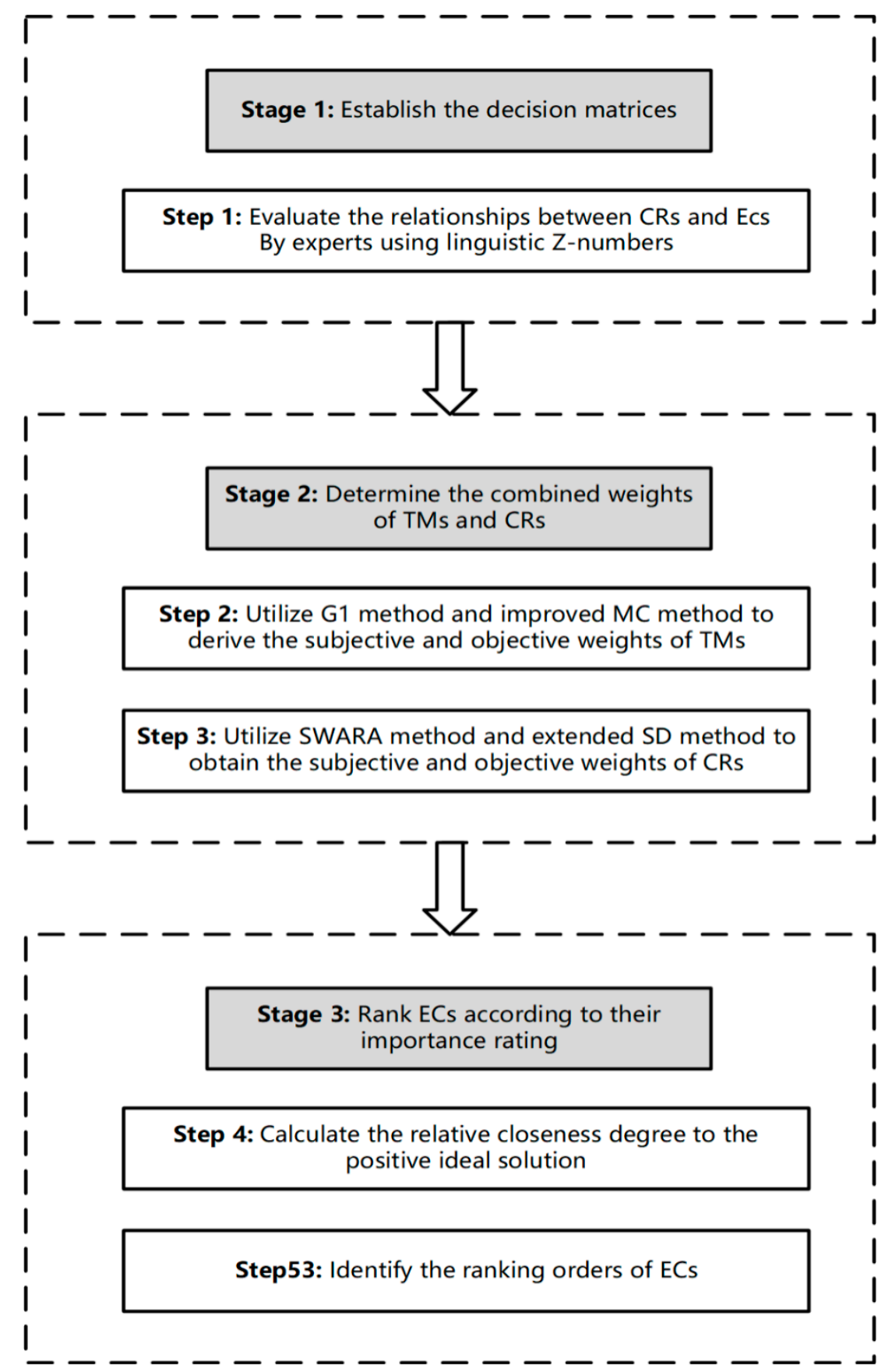

Figure 3. The conceptual framework of the proposed model for QFD.

In order to facilitate the description of the proposed model, we assume that there are $m$ ECs $\left(E C_{i}, i=1,2, \ldots, m\right)$ with respect to $n$ CRs $\left(C R_{j}, j=1,2, \ldots, n\right)$ to be evaluated by $h$ QFD experts TMs $\left(T M_{k}, k=1,2, \ldots, h\right)$. The subjective and objective weight vectors of TMs are $\lambda^{\prime}=\left(\lambda_{1}^{\prime}, \lambda_{2}^{\prime}, \ldots, \lambda_{h}^{\prime}\right)$ and $\lambda^{\prime \prime}=\left(\lambda_{1}^{\prime \prime}, \lambda_{2}^{\prime \prime}, \ldots, \lambda_{h}^{\prime \prime}\right)$, respectively. Further, the subjective and objective weight vectors of CRs are $w^{\prime}=\left(w_{1}^{\prime}, w_{2}^{\prime}, \ldots, w_{n}^{\prime}\right)$ and $w^{\prime \prime}=\left(w_{1}^{\prime \prime}, w_{2}^{\prime \prime}, \ldots, w_{n}^{\prime \prime}\right)$, separately. Moreover, the equalities $\sum_{k=1}^{h} \lambda^{\prime}=\sum_{k=1}^{h} \lambda^{\prime \prime}=1$ and $\sum_{j=1}^{n} w^{\prime}=\sum_{j=1}^{n} w^{\prime \prime}=1$. What's more, the combined weights of TMs and CRs are calculated by the following equations:

$$
\lambda_{k}=\tau \lambda_{k}^{\prime}+(1-\tau) \lambda_{k}^{\prime \prime}, \text { for } k=1,2, \ldots, h,
$$




$$
w_{j}=\xi w_{j}^{\prime}+(1-\xi) w_{j}^{\prime \prime}, \text { for } j=1,2, \ldots, n,
$$

where $0<\tau, \xi<1, \lambda_{k}$ and $w_{j}$ are the integrated weights of $T M_{k}$ and $C R_{j}$, respectively.

Furthermore, let $U^{k}=\left[u_{i j}^{k}\right]_{m \times n}(k=1,2, \ldots, h)$ be the evaluation matrix given by $T M_{k}$ where $u_{i j}^{k}$ is assessed value of $E C_{i}$ with regard to $C R_{j}$. In addition, assume $V=\left[v_{i j}\right]_{m \times n}$ be the collective decision matrix in which $v_{i j}=u_{i j}^{k} \cdot \lambda_{k}$.

\subsection{Identifying the Integrated Weights of TMs}

In this part, the order relation analysis (G1) method and improved maximum consensus (MC) method are utilized to capture the integrated subjective and objective weights of QFD team members.

\subsubsection{Determining the Subjective Weights of TMs}

A deal of subjective weights determining methods has conducted by many scholars. For example, AHP method was employed to derive the criteria weights in the case of tourism environmental impact assessment [35], What's more, Wang, Zhang [45] used multi-criteria group decision-making method to hotel building energy efficiency retrofit project selection. However, all of these subjective weights determining methods have lots of complexity and inconvenience. Thus, the G1 method was proposed by Ruan and Yang [46] as a succinct method to get the subjective weights. Due to G1 method's characteristics, it was applied by Xu, Liu [18] to identify criteria weight vector. In this paper, we utilize G1 method to figure out the weights of TMs subjectively. The detailed steps are shown below.

Step 01. Rank the TMs on the basis of their importance.

The ranking order of TMs, which is denoted by a set $T M=\left\{T M_{1}, \ldots, T M_{k}, \ldots, T M_{h}\right\}$, should be given decreasingly by the leader of them according to their importance.

Step O2. Identify the relative importance degree between adjacent TMs.

Based on a description of the relative importance degree as shown in Table 1 , the relative importance degree $\theta_{k}=\frac{\lambda_{k-1}^{\prime}}{\lambda_{k}^{\prime}}$ of the QFD expert $T M_{k-1}$ and $T M_{k}$ can be determined for $k=2,3, \ldots, h$.

Table 1. The description of the relative importance degree.

\begin{tabular}{cc}
\hline $\boldsymbol{\theta}_{\boldsymbol{k}}$ & Description \\
\hline 1.0 & $T M_{k-1}$ is equally important as $T M_{k}$ \\
1.2 & $T M_{k-1}$ is slightly more important than $T M_{k}$ \\
1.4 & $T M_{k-1}$ is more important than $T M_{k}$ \\
1.6 & $T M_{k-1}$ is strongly more important than $T M_{k}$ \\
1.8 & $T M_{k-1}$ is extremely more important than $T M_{k}$ \\
\hline
\end{tabular}

Step O3. Compute the subjective weights of TMs.

The subjective weights of TMs can be derived by the following equations:

$$
\begin{gathered}
\lambda_{h}^{\prime}=\left(1+\sum_{l=2}^{h} \prod_{k=l}^{h} \theta_{k}\right)^{-1} \\
\lambda_{k}^{\prime}=\prod_{l=k+1}^{h} \theta_{l} \lambda_{h}^{\prime}
\end{gathered}
$$

\subsubsection{Determining the Objective Weights of TMs}

There is a mass of subjectivity when obtaining the weights of QFD team members with only subjective method. Therefore, to avoid much subjectivity, it is quite necessary to derive the weights of TMs as a supplement by an objective method. Inspired by the maximum consensus (MC) method in 
the current literature [19,47], this study proposes an improved MC method which takes both positive and negative ideal assessment into account simultaneously, by contrast, the traditional MC method in related literatures only considers the positive ideal point.

Step M1. Determine the positive and negative ideal assessment matrices.

The average of all QFD team members' evaluation can be deemed as the positive ideal assessment, and the positive ideal assessment matrix is denoted by the following formula:

$$
U^{+}=\left[u_{i j}^{+}\right]_{m \times n}=\left[\frac{1}{h} \stackrel{k=1}{h} u_{i j}^{k}\right]_{m \times n}
$$

There are two negative ideal assessment matrices. One is composed with the maximum evaluation value of an EC with respect to a certain $C R$, and the other consists of the minimum assessment value of an EC regarding a certain CR. Moreover, these two negative ideal assessment matrices can be represented as follows:

$$
\begin{aligned}
U^{\max } & =\left[u_{i j}^{\max }\right]_{m \times n}=\left[\max _{k}\left\{u_{i j}^{k}\right\}\right]_{m \times n} \\
U^{\min } & =\left[u_{i j}^{\min }\right]_{m \times n}=\left[\min _{k}\left\{u_{i j}^{k}\right\}\right]_{m \times n}
\end{aligned}
$$

Step M2. Calculate the distances between every TM's evaluation and ideal assessments.

Based on the distance defined in Definition 7 , the differences between personal evaluation and ideal assessments are shown below:

$$
\begin{aligned}
\operatorname{diff}\left(U^{k}, U^{+}\right) & =\frac{1}{n \times m} \sum_{i=1}^{m} \sum_{j=1}^{n} d\left(u_{i j}^{k}, u_{i j}^{+}\right) \\
\operatorname{diff}\left(U^{k}, U^{m a x}\right) & =\frac{1}{n \times m} \sum_{i=1}^{m} \sum_{j=1}^{n} d\left(u_{i j}^{k}, u_{i j}^{\max }\right) \\
\operatorname{diff}\left(U^{k}, U^{\text {min }}\right) & =\frac{1}{n \times m} \sum_{i=1}^{m} \sum_{j=1}^{n} d\left(u_{i j}^{k}, u_{i j}^{\text {min }}\right)
\end{aligned}
$$

Step M3. Compute the objective weights of QFD team members.

Obviously, the bigger weights can be assigned if the TM's evaluation is closer to positive ideal assessment and farther from any negative ideal assessments. Thus, the objective weights of QFD experts TMs can be identified by the expression below:

$$
\lambda_{k}^{\prime \prime}=\frac{1-\operatorname{diff}\left(U^{k}, U^{+}\right)+\min \left\{\operatorname{diff}\left(U^{k}, U^{\max }\right), \operatorname{diff}\left(U^{k}, U^{\min }\right)\right\}}{\sum_{k=1}^{h}\left(1-\operatorname{diff}\left(U^{k}, U^{+}\right)\right)+\sum_{k=1}^{h} \min \left\{\operatorname{diff}\left(U^{k}, U^{\max }\right), \operatorname{diff}\left(U^{k}, U^{\min }\right)\right\}}
$$

where $k=1,2, \ldots, h$.

\subsection{Identifying the Integrated Weights of $C R s$}

This subsection develops SWARA method and statistical distance (SD) method to obtain subjective and objective weights of CRs, separately. And the integrated weights of CRs are acquired ultimately.

\subsubsection{Determining the Subjective Weights of CRs}

To the best of our knowledge, the SWARA method is adopted widely to derive the weight vector $[20,48]$. For example, the SWARA method was employed to prospect for polymetallic mineralization [49]. Further, Nakhaei, Bitarafan [50] utilized the SWARA method to assess the 
weights of indexes and sub-indexes. Due to SWARA method's practical applicability, this study constructs subjective weights of CRs with this utility method.

Step S1. Rank the CRs according to their importance.

Through QFD experts team members' discussions, the order of CRs concerning importance degree can be provided and the most important $C R$ is listed at the first place. The order is represented by $C R=\left\{C R_{1}, \ldots, C R_{j}, \ldots, C R_{n}\right\}$.

Step S2. Calculate the weighted average comparative importance value of adjacent CRs.

Each QFD expert $T M_{k}$ shall give a comparative importance value of adjacent CRs $s_{j}^{k}$ for $k=$ $1,2, \ldots, h$ and $j=2,3, \ldots, n$. Moreover, the symbol $s_{j}=\lambda_{k} \cdot s_{j}^{k}$ denotes weighted average comparative importance value in which $\lambda_{k}$ is the combined weights of TMs.

Step S3. Determine characteristics of the comparative importance and recalculated weights.

The characteristic of the comparative importance $x_{j}$ and recalculated weight $y_{j}$ for $j=1,2, \ldots, n$ can be computed by Equations (17) and (18)

$$
\begin{gathered}
x_{j}=s_{j}+1, \\
y_{j}=\frac{y_{j-1}}{x_{j}} .
\end{gathered}
$$

Step S4. Determine the final weight.

On the basis of the recalculated weight, the final subjective weight $w_{j}^{\prime}$ for $j=1,2, \ldots, n$ can be calculated by the following formula:

$$
w_{j}^{\prime}=\frac{y_{j}}{\sum_{j=1}^{n} y_{j}} .
$$

\subsubsection{Determining the Objective Weights of CRs}

It is not sufficient to only consider the QFD experts' subjective preference on the weights of CRs. There are many objective weights determination methods, such as maximizing deviation method [51] and entropy weight method [52]. Compared with these methods, statistical distance (SD) method is simple during the process of weight determination. Motivated by relevant researches about SD method, this paper utilizes extended SD method to identify the objective weights of CRs under linguistic Z-number environment.

According to the distance of LZNs introduced in Definition 7, the weights of CRs can be determined by the following formulae:

$$
\begin{gathered}
v_{j}=\frac{1}{m} \stackrel{i=1}{\oplus} v_{i j}, \\
\sigma_{j}^{2}=\frac{1}{m} \sum_{i=1}^{m} d\left(v_{i j}, v_{j}\right)^{2}, \\
w_{j}^{\prime \prime}=\frac{\sigma_{j}^{2}}{\sum_{j=1}^{n} \sigma_{j}^{2}} .
\end{gathered}
$$

\subsection{Prioritizing All the ECs}

In order to rank engineering characteristics (ECs), this subsection extends TOPSIS method into LZNs environment. Next, the algorithm of the extended TOPSIS method is listed below.

Step T1. Identify the positive ideal solution (PIS) and negative ideal solution (NIS).

In terms of the comparison method in Definition 6, PIS and NIS can be defined as:

$$
v_{j}^{+}=\max _{i} v_{i j}, i=1,2, \ldots, m \text { for } j=1,2, \ldots, n,
$$




$$
v_{j}^{-}=\operatorname{minv}_{i} v_{i j}, i=1,2, \ldots, m \text { for } j=1,2, \ldots, n .
$$

Step T2. Calculate the distances between CRs and both PIS and NIS.

Using the distance of LZNs in Definition 7, the distances between CRs and both PIS and NIS can be computed by:

$$
\begin{aligned}
& d_{i}^{+}=\sum_{j=1}^{n} w_{j} d\left(v_{i j}, v_{j}^{+}\right), \text {for } i=1,2, \ldots, m, \\
& d_{i}^{-}=\sum_{j=1}^{n} w_{j} d\left(v_{i j}, v_{j}^{-}\right), \text {for } i=1,2, \ldots, m,
\end{aligned}
$$

where $w_{j}$ is the combined weights of $C R_{j}$.

Step T3. Compute the closeness degrees.

The closeness degree can be calculated by Equation (27)

$$
C_{i}=\frac{d_{i}^{-}}{d_{i}^{-}+d_{i}^{+}}, \text {for } i=1,2, \ldots, m,
$$

It easily can be seen that the bigger is $C_{i}$, the prior is $E C_{i}$ at the ranking order.

\subsection{The Decision-Making Procedures}

The brief steps of the proposed approach are summarized below:

Step 1. Establish the decision matrices.

The evaluation values $u_{i j}^{k}$ should be provided for the relationships between engineering characteristics $E C_{i}(i=1,2, \ldots, m)$ and customer requirements $C R_{j}(j=1,2, \ldots, n)$ by the QFD team members $T M_{k}(k=1,2, \ldots, h)$, in which $u_{i j}^{k}$ is in the form of LZNs.

Step 2. Determine the combined weights of TMs.

This paper employs Equations (8) and (9) to compute the subjective weights of TMs. Then, Equations (10)-(16) are utilized to calculate the objective weights of TMs. Finally, Equation (6) is used to determine the combined weights of TMs $\lambda=\left(\lambda_{1}, \lambda_{2}, \ldots, \lambda_{h}\right)$.

Step 3. Determine the combined weights of CRs.

Equations (17)-(19) are used to calculate the subjective weights of CRs. Next, Equations (20)-(22) are applied to compute the objective weights of CRs. Finally, Equation (7) is utilized to identify the integrated weights of $\mathrm{CRs} w=\left(w_{1}, w_{2}, \ldots, w_{n}\right)$.

Step 4. Calculate the closeness degree.

This paper utilizes Equations (23)-(27) to obtain the closeness degree to positive ideal solution $C_{i}(i=1,2, \ldots, m)$.

Step 5. Obtain the ranking orders of ECs.

The ECs are ranked according to the closeness degree $C_{i}$.

\section{Illustration Example}

In this section, a logistics service provider (LSP) [53] is absorbed as a case example to illustrate the effectiveness and efficiency of the proposed QFD model.

\subsection{Problem Description}

As the market changes rapidly and the customer demand shifts unpredictably, the LSP faces more and more serious challenges. For instance, many clients request better service with shorter delivery time, greater order accuracy and lower service cost. That is, in order to maintain core competitiveness, LSP should transform the traditional operations to just-in-time service. In this sense, it is essential to have research on the operations by taking customer requirements into accounts. Owing to the features of QFD model, this paper uses the proposed MCDM approach to determine the importance ratings of operation characteristics according to customer service demands. 
In the case, three experts are selected as the QFD team members, including a senior manager of quality control $T M_{1}$, a representative of the client $T M_{2}$, and a professor of industry engineering $T M_{3}$. After a mass of investigations and discussions, six customer requirements $\left(C R_{1}, C R_{2}, C R_{3}, C R_{4}, C R_{5}, C R_{6}\right)$ and eight engineering characteristics $\left(E C_{1}, E C_{2}, E C_{3}, E C_{4}, E C_{5}, E C_{6}, E C_{7}, E C_{8}\right)$ are defined for LSP as shown in Table 2.

Table 2. CRs and ECs in the case study.

\begin{tabular}{lccc}
\hline CRs & Customer Requirements & ECs & Engineering Characteristics \\
\hline$C R_{1}$ & Lead-time & $E C_{1}$ & Just-in time \\
$C R_{2}$ & Accuracy & $E C_{2}$ & Information technology \\
$C R_{3}$ & Fill rate & $E C_{3}$ & Order picking optimization \\
$C R_{4}$ & Flexibility & $E C_{4}$ & Demand forecasting methods \\
$C R_{5}$ & Reliability & $E C_{5}$ & Quality of services \\
$C R_{6}$ & Frequency & $E C_{6}$ & Customer relationship management \\
& & $E C_{7}$ & Warehouses lay-out optimization \\
& $E C_{8}$ & Information sharing and mutual trust \\
\hline
\end{tabular}

\subsection{Implementation of the Proposed Model}

In this part, the proposed QFD model considering combined subjective and objective weights is applied for the case of LSP.

Step 1. Establish the decision matrices.

Since LZNs can express fuzzy and uncertain information perfectly, it is employed to evaluate the relationships between CRs and ECs by QFD expert team members. For a LZN $Z=\langle A, B\rangle$, the fuzzy restriction $A$ is a linguistic term in set $S_{1}$ :

$$
s_{1}=\left\{\begin{array}{l}
s_{0}=\text { Very low }, s_{1}=\text { low }, s_{2}=\text { Medium low }, s_{3}=\text { Medium, } \\
s_{4}=\text { Medium high, } s_{5}=\text { High }, s_{6}=\text { Very High }
\end{array}\right\} ;
$$

Meanwhile, the reliability measure $B$ is a linguistic term in set $S_{2}$ :

$$
S_{2}=\left\{s_{0}^{\prime}=\text { Uncertain, } s_{1}^{\prime}=\text { Slightly Uncertain, } s_{2}^{\prime}=\text { Medium, } s_{3}^{\prime}=\text { Slightly Sure, } s_{4}^{\prime}=\text { Sure }\right\}
$$

The relationship evaluation information between CRs and ECs is represented in Table 3 given by three QFD experts.

Step 2. Determine the combined weights of TMs.

(1) The CEO of LSP thinks that the senior manager of quality control $T M_{1}$ accounts for the maximum weights and the professor of industry engineering $T M_{3}$ is designate as the minimum weights. Further, the relative importance degrees provided by CEO are $\theta_{2}=1.2$ and $\theta_{3}=1.8$ according to Table 1. By the means of Equations (8) and (9), the subjective weight vector of TMs are $\lambda^{\prime}=(0.4355,0.3629,0.2016)^{T}$.

(2) On the basis of the operational method and comparison method of LZNs in Definition 5 and

(3) Definition 6, the ideal assessments can be obtained as shown in Tables 4-6. The differences between personal evaluation of TMs and ideal assessments can be computed by Equations (13)-(15). The calculated results are listed below:

$$
\begin{gathered}
\operatorname{diff}\left(U^{1}, U^{+}\right)=0.1758 ; \operatorname{diff}\left(U^{2}, U^{+}\right)=0.1166 ; \operatorname{diff}\left(U^{3}, U^{+}\right)=0.1626 ; \\
\operatorname{diff}\left(U^{1}, U^{\max }\right)=0.1997 ; \operatorname{diff}\left(U^{2}, U^{\max }\right)=0.1814 ; \operatorname{diff}\left(U^{3}, U^{\max }\right)=0.1749 \\
\operatorname{diff}\left(U^{1}, U^{\min }\right)=0.1623 ; \operatorname{diff}\left(U^{2}, U^{\min }\right)=0.1823 ; \operatorname{diff}\left(U^{3}, U^{\min }\right)=0.1984
\end{gathered}
$$


By Equation (16), the objective weights vector of TMs can be determined a $\lambda^{\prime \prime}=$ $(0.3220,0.3476,0.3304)^{T}$.

(4) From the above analyses, we assume that the preference coefficient $\tau$ is 0.5 , the integrated weights of TMs can be identified by Equation (6) which is $\lambda=(0.3788,0.3552,0.2660)^{T}$.

Table 3. The relationship evaluation information between CRs and ECs.

\begin{tabular}{|c|c|c|c|c|c|c|c|c|c|}
\hline & & $E C_{1}$ & $E C_{2}$ & $E C_{3}$ & $E C_{4}$ & $E C_{5}$ & $E C_{6}$ & $E C_{7}$ & $E C_{8}$ \\
\hline \multirow{5}{*}{$T M_{1}$} & $C R_{1}$ & $\left\langle s_{5}, s_{3}^{\prime}\right\rangle$ & $\left\langle s_{6}, s_{4}^{\prime}\right\rangle$ & $\left\langle s_{2}, s_{4}^{\prime}\right\rangle$ & $\left\langle s_{0}, s_{2}^{\prime}\right\rangle$ & $\left\langle s_{1}, s_{0}^{\prime}\right\rangle$ & $\left\langle s_{1}, s_{3}^{\prime}\right\rangle$ & $\left\langle s_{2}, s_{3}^{\prime}\right\rangle$ & \\
\hline & $C R_{2}$ & $\left\langle s_{4}, s_{3}^{\prime}\right\rangle$ & $\left\langle s_{3}, s_{4}^{\prime}\right\rangle$ & $s_{0}, s_{1}^{\prime}$ & $\left\langle s_{0}, s_{2}^{\prime}\right\rangle$ & $\left.s_{2}^{\prime}\right\rangle$ & & & \\
\hline & $C R_{3}$ & $\left\langle s_{1}, s_{3}^{\prime}\right\rangle$ & $\left\langle s_{4}, s_{3}^{\prime}\right\rangle$ & $\left.s_{0}, s_{1}^{\prime}\right\rangle$ & $\left\langle s_{3}, s_{2}^{\prime}\right\rangle$ & & & & \\
\hline & & & & & & & & & \\
\hline & & & & & & & & & \\
\hline \multirow{6}{*}{$T M_{2}$} & $C R_{1}$ & $\left\langle s_{3}, s^{\prime}\right\rangle$ & $\left\langle s_{5}, s_{1}^{\prime}\right\rangle$ & $s_{3} s_{3} s_{n}^{\prime}$ & $\left\langle s_{2}, s_{2}^{\prime}\right\rangle$ & $\left\langle s_{2}, s_{0}^{\prime}\right\rangle$ & $\left\langle s_{2}, s_{0}^{\prime}\right\rangle$ & & \\
\hline & $C R_{2}$ & $\left\langle s_{6}, s_{2}^{\prime}\right\rangle$ & $\left\langle s_{2}, s_{3}^{\prime}\right\rangle$ & & & & & & \\
\hline & $C R_{3}$ & $\left\langle s_{2}, s_{2}^{\prime}\right\rangle$ & $\left\langle s_{2}, s_{4}^{\prime}\right\rangle$ & $\left\langle s_{1}, s_{0}^{\prime}\right\rangle$ & $\left\langle s_{4}, s_{3}^{\prime}\right\rangle$ & $\left.s_{1}^{\prime}\right\rangle$ & & & \\
\hline & $C R_{4}$ & $\left\langle s_{4}, s_{2}^{\prime}\right\rangle$ & $\left\langle s_{3}, s_{2}^{\prime}\right\rangle$ & $\left\langle s_{1}, s_{2}^{\prime}\right\rangle$ & $\left\langle s_{3}, s_{4}^{\prime}\right\rangle$ & & & & \\
\hline & $C R_{5}$ & $\left\langle s_{6}, s_{2}^{\prime}\right\rangle$ & $\left\langle s_{5}, s_{2}^{\prime}\right\rangle$ & $\left\langle s_{0}, s_{3}^{\prime}\right\rangle$ & $\left\langle s_{1}, s_{2}^{\prime}\right\rangle$ & $s_{2}^{\prime}$ & & & \\
\hline & $C R_{6}$ & $\left\langle s_{3}, s_{2}^{\prime}\right\rangle$ & $\left\langle s_{1}, s_{2}^{\prime}\right\rangle$ & $\left\langle s_{5}, s_{2}^{\prime}\right\rangle$ & $\left\langle s_{3}, s_{2}^{\prime}\right\rangle$ & $\left\langle s_{4}, s_{3}^{\prime}\right\rangle$ & $\left\langle s_{2}, s_{1}^{\prime}\right\rangle$ &,$\left.s_{0}^{\prime}\right\rangle$ & \\
\hline \multirow{6}{*}{$T M_{3}$} & $C R_{1}$ & $\left\langle s_{3}, s_{3}^{\prime}\right\rangle$ & $\left\langle s_{4}, s_{3}^{\prime}\right\rangle$ & $\left\langle s_{2}, s_{1}^{\prime}\right\rangle$ & $\left\langle s_{0}, s_{3}^{\prime}\right\rangle$ & $\left\langle s_{1}, s_{2}^{\prime}\right\rangle$ & & & \\
\hline & $C R_{2}$ & $\left\langle s_{5}, s_{3}^{\prime}\right\rangle$ & & & $\left\langle s_{2}, s_{4}^{\prime}\right\rangle$ & $\left\langle s_{1}, s_{1}^{\prime}\right\rangle$ & & & \\
\hline & $C R_{3}$ & $\left\langle s_{4}, s_{1}^{\prime}\right\rangle$ & & & & $\left\langle s_{3}, s_{3}^{\prime}\right\rangle$ & & & \\
\hline & $C R_{4}$ & $\left\langle s_{3}, s_{1}^{\prime}\right\rangle$ & $\left\langle s_{4}, s_{1}^{\prime}\right\rangle$ & & & & & & \\
\hline & $C R_{5}$ & $\left\langle s_{5}, s_{2}^{\prime}\right\rangle$ & $\left\langle s_{4}, s_{1}^{\prime}\right\rangle$ & $\left\langle s_{1}, s_{2}^{\prime}\right\rangle$ & $\left\langle s_{2}, s_{3}^{\prime}\right\rangle$ & $\left\langle s_{1}, s_{3}^{\prime}\right\rangle$ & $\left\langle s_{1}, s_{1}^{\prime}\right\rangle$ &,$\left.s_{2}^{\prime}\right\rangle$ & \\
\hline & $C R_{6}$ & $\left\langle s_{2}, s_{4}^{\prime}\right\rangle$ & $\left\langle s_{3}, s_{0}^{\prime}\right\rangle$ & $\left\langle s_{6}, s_{3}^{\prime}\right\rangle$ & $\left\langle s_{4}, s_{1}^{\prime}\right\rangle$ & $\left\langle s_{5}, s_{1}^{\prime}\right\rangle$ & $\left\langle s_{1}, s_{3}^{\prime}\right\rangle$ & $\left\langle s_{2}, s_{2}^{\prime}\right\rangle$ & \\
\hline
\end{tabular}

Table 4. The positive ideal assessment.

\begin{tabular}{|c|c|c|c|c|c|c|c|c|}
\hline & $E C_{1}$ & $E C_{2}$ & $E C_{3}$ & $E C_{4}$ & $E C_{5}$ & $E C_{6}$ & $E C_{7}$ & $E C_{8}$ \\
\hline$C R_{1}$ & $\left\langle s_{3.67}, s_{3.27}^{\prime}\right\rangle$ & $\left\langle s_{5.00}, s_{2.73}^{\prime}\right\rangle$ & $\left\langle s_{2.33}, s_{2.29}^{\prime}\right\rangle$ & $\left\langle s_{0.67}, s_{3.00}^{\prime}\right\rangle$ & $\left\langle s_{1.33}, s_{1.50}^{\prime}\right\rangle$ & $\left\langle s_{2.00}, s_{1.00}^{\prime}\right\rangle$ & $\left.{ }_{3}, s_{2.75}^{\prime}\right\rangle$ & $\left\langle s_{1.33}, s_{2.25}^{\prime}\right\rangle$ \\
\hline$C R_{2}$ & $\left\langle s_{5.00}, s_{2.60}^{\prime}\right\rangle$ & $\left\langle s_{2.00}, s_{3.33}^{\prime}\right\rangle$ & $\left\langle s_{1.67}, s_{1.60}^{\prime}\right\rangle$ & $\left\langle s_{1.00}, s_{3.67}^{\prime}\right\rangle$ & $\left.33, s_{1.75}^{\prime}\right\rangle$ & $\left\langle s_{1.00}, s_{1.67}^{\prime}\right\rangle$ & & $\left\langle s_{5.67}, s_{3.41}^{\prime}\right\rangle$ \\
\hline$C R_{3}$ & $\left.s_{1.57}^{\prime}\right\rangle$ & $\left.s_{3.29}^{\prime}\right\rangle$ &,$\left.s_{0.00}^{\prime}\right\rangle$ & $\left\langle s_{4.00}, s_{3.17}^{\prime}\right\rangle$ &,$\left.s_{1.83}^{\prime}\right\rangle$ & $\left\langle s_{2.33}, s_{1.29}^{\prime}\right\rangle$ & & $\left.s_{1.56}^{\prime}\right\rangle$ \\
\hline$C R_{4}$ & $\left.00, s_{2.17}^{\prime}\right\rangle$ & $\left..67, s_{1.27}^{\prime}\right\rangle$ & $\left.s_{2.67}^{\prime}\right\rangle$ & $\left\langle s_{2.00}, s_{3.00}^{\prime}\right\rangle$ & $\left\langle s_{2.00}, s_{0.33}^{\prime}\right\rangle$ & $\left\langle s_{4.67}, s_{2.00}^{\prime}\right\rangle$ & & $\left.s_{4.00}^{\prime}\right\rangle$ \\
\hline$C R_{5}$ & $\left.00, s_{2.53}^{\prime}\right\rangle$ & $\left\langle s_{4.33}, s_{1.38}^{\prime}\right\rangle$ &,$\left.s_{2.00}^{\prime}\right\rangle$ & $\left\langle s_{1.67}, s_{2.80}^{\prime}\right\rangle$ & $\left\langle s_{1.33}, s_{2.25}^{\prime}\right\rangle$ & $\left\langle s_{1.00}, s_{0.33}^{\prime}\right\rangle$ & $\left.33, s_{2.25}^{\prime}\right\rangle$ & $\left\langle s_{3.33}, s_{2.30}^{\prime}\right\rangle$ \\
\hline$C R_{6}$ & $\left\langle s_{3.00}, s_{2.00}^{\prime}\right\rangle$ & $\left\langle s_{2.00}, s_{1.00}^{\prime}\right\rangle$ & $\left\langle s_{5.00}, s_{2.67}^{\prime}\right\rangle$ & $\left\langle s_{2.67}, s_{1.38}^{\prime}\right\rangle$ & $\left\langle s_{4.67}, s_{1.93}^{\prime}\right\rangle$ & $\left\langle s_{1.33}, s_{1.25}^{\prime}\right\rangle$ & $\left\langle s_{3.00}, s_{1.33}^{\prime}\right\rangle$ & $\left\langle s_{0.33}, s_{3.00}^{\prime}\right\rangle$ \\
\hline
\end{tabular}

Table 5. The negative ideal assessment-maximum value.

\begin{tabular}{|c|c|c|c|c|c|c|c|c|}
\hline & $E C_{1}$ & $E C_{2}$ & $E C_{3}$ & $E C_{4}$ & $E C_{5}$ & $E C_{6}$ & $E C_{7}$ & $E C_{8}$ \\
\hline$C R_{1}$ & $\left\langle s_{5}, s_{3}^{\prime}\right\rangle$ & $\left\langle s_{6}, s_{4}^{\prime}\right\rangle$ & $\left\langle s_{2}, s_{4}^{\prime}\right\rangle$ & $\left\langle s_{2}, s_{3}^{\prime}\right\rangle$ & $\left\langle s_{2}, s_{2}^{\prime}\right.$ & $\left\langle s_{3}, s_{1}^{\prime}\right\rangle$ & $\left\langle s_{2}, s_{3}^{\prime}\right\rangle$ & $\left\langle s_{2}, s_{2}^{\prime}\right\rangle$ \\
\hline$C R_{2}$ & $\left\langle s_{5}, s_{3}^{\prime}\right\rangle$ & & $\left\langle s_{3}, s_{2}^{\prime}\right\rangle$ & $\left\langle s_{2}, s_{4}^{\prime}\right\rangle$ & $s_{2}, s_{2}^{\prime}$ & $\left\langle s_{2}, s_{2}^{\prime}\right\rangle$ & & $\left\langle s_{6}, s_{4}^{\prime}\right\rangle$ \\
\hline $\mathrm{CR}_{3}$ & $\left\langle s_{4}, s_{1}^{\prime}\right\rangle$ & $\left\langle s_{4}, s_{3}^{\prime}\right\rangle$ & $\left\langle s_{1}, s_{0}^{\prime}\right\rangle$ & $\left\langle s_{5}, s_{4}^{\prime}\right\rangle$ & $s_{3}, s_{3}^{\prime}$ & & & $\left\langle s_{3}, s_{2}^{\prime}\right\rangle$ \\
\hline$C R_{4}$ & $\left\langle s_{5}, s_{3}^{\prime}\right\rangle$ & $\left\langle s_{3}, s_{2}^{\prime}\right\rangle$ & $\left\langle s_{2}, s_{3}^{\prime}\right\rangle$ & $\left\langle s_{3}, s_{4}^{\prime}\right\rangle$ & $s_{2}, s_{1}^{\prime}$ & $\left\langle s_{3}, s_{4}^{\prime}\right\rangle$ & $\left.s_{2}^{\prime}\right\rangle$ & $\left\langle s_{4}, s_{4}^{\prime}\right\rangle$ \\
\hline$C R_{5}$ & $\left\langle s_{4}, s_{4}^{\prime}\right\rangle$ & $\left\langle s_{5}, s_{2}^{\prime}\right\rangle$ & $\left\langle s_{1}, s_{2}^{\prime}\right\rangle$ & $\left\langle s_{2}, s_{3}^{\prime}\right\rangle$ & $s_{2}, s_{2}^{\prime}$ & & & $\left\langle s_{3}, s_{4}^{\prime}\right\rangle$ \\
\hline$C R_{6}$ & $\left\langle s_{2}, s_{4}^{\prime}\right\rangle$ & $\left\langle s_{2}, s_{2}^{\prime}\right\rangle$ & $\left\langle s_{6}, s_{3}^{\prime}\right\rangle$ & $\left\langle s_{3}, s_{2}^{\prime}\right\rangle$ & $\left\langle s_{4}, s_{3}^{\prime}\right.$ & $\left\langle s_{1}, s_{3}^{\prime}\right\rangle$ & $\left\langle s_{4}, s_{2}^{\prime}\right\rangle$ & $\left\langle s_{1}, s_{3}^{\prime}\right\rangle$ \\
\hline
\end{tabular}


Table 6. The negative ideal assessment-minimum value.

\begin{tabular}{|c|c|c|c|c|c|c|c|c|}
\hline & $E C_{1}$ & $E C_{2}$ & $E C_{3}$ & $E C_{4}$ & $E C_{5}$ & $E C_{6}$ & $E C_{7}$ & $E C_{8}$ \\
\hline$C R_{1}$ & $\left\langle s_{3}, s_{3}^{\prime}\right\rangle$ & $\left\langle s_{5}, s_{1}^{\prime}\right\rangle$ & $\left\langle s_{2}, s_{1}^{\prime}\right\rangle$ & $\left\langle s_{0}, s_{3}^{\prime}\right.$ & $\left\langle s_{1}, s_{0}^{\prime}\right\rangle$ & $\left\langle s_{2}, s_{0}^{\prime}\right\rangle$ & $\left\langle s_{1}, s_{2}^{\prime}\right\rangle$ & $\left\langle s_{1}, s_{2}^{\prime}\right\rangle$ \\
\hline$C R_{2}$ & $\left\langle s_{4}, s_{3}^{\prime}\right\rangle$ & $\left\langle s_{1}, s_{2}^{\prime}\right\rangle$ & $\left\langle s_{0}, s_{1}^{\prime}\right\rangle$ & & $\left\langle s_{1}, s_{1}^{\prime}\right\rangle$ & & &,$\left.s_{2}^{\prime}\right\rangle$ \\
\hline $\mathrm{CR}_{3}$ & $\left\langle s_{1}, s_{3}^{\prime}\right\rangle$ & $\left\langle s_{1}, s_{3}^{\prime}\right\rangle$ & $\left\langle s_{0}, s_{2}^{\prime}\right\rangle$ & & $\left\langle s_{1}, s_{0}^{\prime}\right\rangle$ & & $\left\langle s_{0}, s_{4}^{\prime}\right\rangle$ & $\left.{ }^{\prime} s_{3}^{\prime}\right\rangle$ \\
\hline$C R_{4}$ & $\left\langle s_{3}, s_{1}^{\prime}\right\rangle$ & $\left\langle s_{4}, s_{1}^{\prime}\right\rangle$ & $\left\langle s_{0}, s_{1}^{\prime}\right\rangle$ & $s_{2}^{\prime}$ & $\left\langle s_{0}, s_{2}^{\prime}\right\rangle$ & & $\left\langle s_{0}, s_{3}^{\prime}\right\rangle$ & $\left.s_{4}^{\prime}\right\rangle$ \\
\hline$C R_{5}$ & $\left\langle s_{5}, s_{2}^{\prime}\right\rangle$ & $\left\langle s_{4}, s_{1}^{\prime}\right\rangle$ & $\left\langle s_{0}, s_{3}^{\prime}\right\rangle$ & & & & $\left\langle s_{1}, s_{2}^{\prime}\right\rangle$ & $\left\langle s_{3}, s_{1}^{\prime}\right\rangle$ \\
\hline$C R_{6}$ & $\left\langle s_{4}, s_{1}^{\prime}\right\rangle$ & $\left\langle s_{3}, s_{0}^{\prime}\right\rangle$ & $\left\langle s_{5}, s_{2}^{\prime}\right\rangle$ & $\left\langle s_{1}, s_{1}^{\prime}\right.$ & $\left\langle s_{5}, s_{1}^{\prime}\right\rangle$ & $\left\langle s_{1}, s_{0}^{\prime}\right\rangle$ & $\left\langle s_{3}, s_{0}^{\prime}\right\rangle$ & $\left\langle s_{0}, s_{2}^{\prime}\right\rangle$ \\
\hline
\end{tabular}

Step 3. Determine the combined weights of CRs.

(1) With QFD experts' consultations, CRs are sorted according to their importance and the descending order is Lead-time $C R_{1}$, Accuracy $C R_{2}$, Reliability $C R_{5}$, Fill rate $C R_{3}$, Flexibility $C R_{4}$, and Frequency $C R_{6}$. Next, the comparative importance values between adjacent CRs are provided which are declared in Table 7. Finally, the subjective weights of CRs can be derived by Equations (17) and (19), the results are shown in Table 8. That is, CRs' subjective weight vector is $w^{\prime}=(0.32,0.24,0.12,0.10,0.15,0.07)^{T}$.

(2) The comprehensive decision matrix, as shown in Table 9, can be obtained by integrating the weights of QFD experts and their evaluation values. According to the Equations (20)-(22), the objective weights vector of CRs is $w^{\prime \prime}=(0.1641,0.2669,0.1353,0.1546,0.1519,0.1272)^{T}$.

(3) We suppose that the preference coefficient $\xi$ is 0.5 , then the combined weights vector of CRs is calculated by Equation $(7)$ which is $w^{\prime \prime}=(0.2421,0.2534,0.1277,0.1273,0.1509,0.0986)^{T}$.

Table 7. The comparative importance values between adjacent CRs.

\begin{tabular}{cccccc}
\hline & $C R_{1 \leftrightarrow 2}$ & $C_{2 \leftrightarrow 5}$ & $C R_{5 \leftrightarrow 3}$ & $C_{2} R_{3 \leftrightarrow 4}$ & $C_{4 \leftrightarrow 6}$ \\
\hline $\mathrm{TM}_{1}$ & 0.20 & 0.60 & 0.10 & 0.00 & 0.50 \\
$\mathrm{TM}_{2}$ & 0.40 & 0.50 & 0.30 & 0.40 & 0.70 \\
$\mathrm{TM}_{3}$ & 0.50 & 0.60 & 0.40 & 0.30 & 0.40 \\
\hline
\end{tabular}

Table 8. The final subjective weights of CRs.

\begin{tabular}{lcccc}
\hline & $\begin{array}{c}\text { Weighted Average } \\
\text { Comparative } \\
\text { Importance Value } s_{j}\end{array}$ & $\begin{array}{c}\text { The Characteristic of } \\
\text { the Comparative } \\
\text { Importance } x_{j}\end{array}$ & $\begin{array}{c}\text { The Recalculated } \\
\text { Weight } y_{j}\end{array}$ & $\begin{array}{c}\text { The Final Subjective } \\
\text { Weight } \boldsymbol{w}_{j}^{\prime}\end{array}$ \\
\hline$C R_{1}$ & - & 1.00 & 1.00 & 0.32 \\
$C R_{2}$ & 0.35 & 1.35 & 0.74 & 0.24 \\
$C R_{5}$ & 0.56 & 1.56 & 0.47 & 0.15 \\
$C R_{3}$ & 0.25 & 1.25 & 0.38 & 0.12 \\
$C R_{4}$ & 0.22 & 1.22 & 0.31 & 0.10 \\
$C R_{6}$ & 0.54 & 1.54 & 0.20 & 0.07 \\
\hline
\end{tabular}

Table 9. The comprehensive decision matrix.

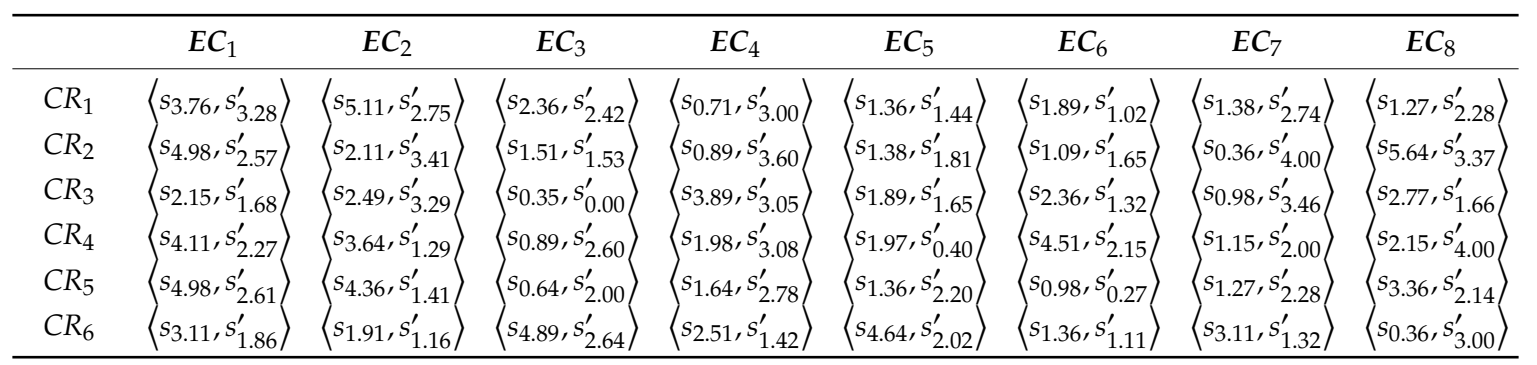


Step 4. Calculate the closeness degree.

Drawing on the comparison method in Definition 6, the PIS and NIS of engineering characteristics (EC) are acquired as follows:

$$
\begin{aligned}
& v^{+}=\left\{\left\langle s_{5.11}, s_{2.75}^{\prime}\right\rangle,\left\langle s_{5.64}, s_{3.37}^{\prime}\right\rangle,\left\langle s_{3.89}, s_{3.05}^{\prime}\right\rangle,\left\langle s_{4.51}, s_{2.15}^{\prime}\right\rangle,\left\langle s_{4.98}, s_{2.61}^{\prime}\right\rangle,\left\langle s_{4.89}, s_{2.64}^{\prime}\right\rangle\right\} ; \\
& v^{-}=\left\{\left\langle s_{1.89}, s_{1.02}^{\prime}\right\rangle,\left\langle s_{0.36}, s_{4.00}^{\prime}\right\rangle,\left\langle s_{0.36}, s_{0.00}^{\prime}\right\rangle,\left\langle s_{1.77}, s_{0.40}^{\prime}\right\rangle,\left\langle s_{0.98}, s_{0.27}^{\prime}\right\rangle,\left\langle s_{0.36}, s_{3.00}^{\prime}\right\rangle\right\} .
\end{aligned}
$$

The closeness degrees $C_{i}$ can be computed for $i=1,2, \ldots, m$ by Equations (25)-(27) which are illustrated in Table 10.

Table 10. The closeness degrees of ECs.

\begin{tabular}{ccccccccc}
\hline & $E C_{1}$ & $E C_{2}$ & $E C_{3}$ & $E C_{4}$ & $E C_{5}$ & $E C_{6}$ & $E C_{7}$ & $E C_{8}$ \\
\hline$d_{i}^{+}$ & 0.1723 & 0.2790 & 0.5029 & 0.4765 & 0.5046 & 0.5069 & 0.5533 & 0.3080 \\
$d_{i}^{-}$ & 0.4901 & 0.3845 & 0.2806 & 0.3054 & 0.2195 & 0.1829 & 0.2301 & 0.4213 \\
$C_{i}$ & 0.7399 & 0.5794 & 0.3581 & 0.3906 & 0.3031 & 0.2652 & 0.2937 & 0.5777 \\
\hline
\end{tabular}

Step 5. Obtain the ranking orders of ECs.

In terms of the closeness degrees of ECs, the ranking order of ECs is $E C_{1}>E C_{2}>E C_{8}>E C_{4}>$ $E C_{3}>E C_{5}>E C_{7}>E C_{6}$. Note that the most important three ECs are Just-in time $E C_{1}, A_{c c u r a c y} E C_{2}$, and Frequency $E C_{8}$.

\subsection{Sensitivity Analysis}

This subsection studies a sensitivity analysis of different LSFs is.

In the proposed QFD model, three LSFs are absorbed to deal with linguistic terms of the utilized LZNs. If different LSFs are employed, different ranking results of ECs may be obtained. Thus, we should alter the LSFs to see how the ranking orders are varied. What's more, for a $\operatorname{LN} Z=\langle A, B\rangle$, the fuzzy restriction $A$ is a linguistic term which expresses the correlation degree between CRs and ECs in this paper while the reliability measure $B$ is the uncertainty estimation of $A$ provided by TMs. Namely, it is worth noting that two parts of LZNs describe disparate evaluation preferences. Therefore, the two components of LZNs may choose different LSFs.

On the one hand, we use the first LSF $f_{1}$ to handle the fuzzy restriction $A$ and change the LSFs to dispose reliability measure $B$. On the other hand, different LSFs are utilized to transform linguistic information $A$ to a numeric value and the LSF of linguistic term $B$ is always $f_{1}$. The results are offered in Table 11.

Table 11. Ranking results with different LSFs.

\begin{tabular}{cll}
\hline$f^{*}(\boldsymbol{A})$ & \multicolumn{1}{c}{$\boldsymbol{g}^{*}(\boldsymbol{B})$} & \multicolumn{1}{c}{ Ranking Results } \\
\hline$f^{*}(A)=f_{1}(A)$ & $g^{*}(B)=f_{1}(B)$ & $E C_{1}>E C_{2}>E C_{8}>E C_{4}>E C_{3}>E C_{5}>E C_{7}>E C_{6}$ \\
$f^{*}(A)=f_{1}(A)$ & $g^{*}(B)=f_{2}(B)$ & $E C_{1}>E C_{2}>E C_{8}>E C_{4}>E C_{3}>E C_{5}>E C_{6}>E C_{7}$ \\
$f^{*}(A)=f_{1}(A)$ & $g^{*}(B)=f_{3}(B)$ & $E C_{1}>E C_{2}>E C_{8}>E C_{4}>E C_{3}>E C_{5}>E C_{7}>E C_{6}$ \\
\hline$f^{*}(A)=f_{1}(A)$ & $g^{*}(B)=f_{1}(B)$ & $E C_{1}>E C_{2}>E C_{8}>E C_{4}>E C_{3}>E C_{5}>E C_{7}>E C_{6}$ \\
$f^{*}(A)=f_{2}(A)$ & $g^{*}(B)=f_{1}(B)$ & $E C_{1}>E C_{8}>E C_{2}>E C_{4}>E C_{3}>E C_{7}>E C_{5}>E C_{6}$ \\
$f^{*}(A)=f_{3}(A)$ & $g^{*}(B)=f_{1}(B)$ & $E C_{1}>E C_{2}>E C_{8}>E C_{4}>E C_{3}>E C_{5}>E C_{7}>E C_{6}$ \\
\hline
\end{tabular}

As the results shown in Table 11, no matter how the utilized LSFs of the fuzzy restriction $A$ and reliability measure $B$ change, the Just-in time $E C_{1}$, Accuracy $E C_{2}$, and Frequency $E C_{8}$ are always the three engineering characteristics needed to pay close attention to mostly. As a consequence, the robustness of proposed QFD model can be concluded. 


\subsection{Comparative Analysis}

In this subsection, two cases of comparative analysis are conducted to demonstrate the validity and practicality of the developed model in this study. One is to compare the proposed method with state-of -the-art MCDM method using LZNs. The other is to make a comparison between the proposed QFD model and other QFD models.

Case 1: The proposed method is compared with existing methods under LZNs environment.

At present, only one MCDM method is investigated with LZNs [16]. In this method, Wang et al. defined the distance measure of LZNs and extended the TODIM method based on Choquet Integral and distance measure. Hence, Wang et al.'s method is applied in the LSP example to find the most significant engineering characteristics. However, since the criteria weights were confirmed by a subjective method by Wang et al., the weights are assigned as the combined weights of CRs in this study. And the ranking orders of ECs are presented in Table 12.

Table 12. The comparison between the proposed method and existing methods utilizing LZNs.

\begin{tabular}{cc}
\hline Method & Rank Orders \\
\hline Wang et al.'s method $(\theta=1)[16]$ & $E C_{1}>E C_{2}>E C_{8}>E C_{4}>E C_{3}>E C_{7}>E C_{5}>E C_{6}$ \\
The proposed method $\left(f^{*}(A)=f_{1}(A), g^{*}(B)=f_{1}(B)\right)$ & $E C_{1}>E C_{2}>E C_{8}>E C_{4}>E C_{3}>E C_{5}>E C_{7}>E C_{6}$ \\
\hline
\end{tabular}

From Table 12, the most vital engineering characteristic is $E C_{1}$ and the least crucial engineering characteristic is $E C_{6}$ for the both methods with LZNs. As a result, the feasibility of proposed method is proved. Meanwhile, there are two differences between these two methods. The first is that the computations of two methods are diverse. Wang et al.'s method needed to calculate the dominance degree of one engineering characteristic over another engineering characteristic with respect to a certain customer requirement. In other words, it should make a comparison between each pair of engineering characteristic regarding every customer requirement. However, if a lot of ECs are adopted in the case of LSP, it will cause the calculated amounts of Wang et al.'s method increase tremendously. By contrast, the proposed method only requires comparing engineering characteristics with PIS and NIS which haves less calculated quantities. The second is that the weights determining methods of CRs are distinctive in these two methods using LZNs. Wang et al. employed a subjective method to identify the weights. Nevertheless, in the practical processes, it is not enough to derive weights only by a subjective method. The objective weights determining methods are also wanted just like the proposed method does in this paper. In conclusion, the proposed method is more likely to be applied in real-life cases than Wang et al.'s method. Thus, the utility of proposed method is validated.

Case 2: The proposed QFD model is compared with extant QFD models.

For all we know, many MCDM approaches have been integrated into conventional QFD models to address the problems of them $[3,6,54]$. In order to demonstrate the strength of proposed QFD model, these QFD models are selected to do a comparative analysis. However, Yazdani et al. [6], Liao and Kao [54], Wu et al. [3], and this paper use crisp numbers (CNs), triangular fuzzy numbers (TFNs), hesitant fuzzy numbers (HFNs), and LZNs for evaluation information representations, separately. Namely, it is hard to compare these QFD models in the examples of this study due to different information expressions. Thus, we only make a comparison of the frameworks among these integrated QFD models. Furthermore, the frameworks of QFD models [3,6,54] are declared in Table 13.

As we can see in Table 13, Yazdani et al. [6] utilized crisp numbers to describe the relationship between CRs and ECs. Meanwhile, Liao and Kao [54] and Wu et al. [3] employed fuzzy numbers for information description. By contrast, this paper uses LZNs to denote the correlation between CRs and ECs. As for the weights of TMs, Wu et al. [3] only took objective weighting method into accounts while this paper considers both subjective and objective weighting method. What's more, as for the weights of CRs, Yazdani et al. [6], Liao and Kao [54], and Wu et al. [3] determined the weights of CRs 
by merely subjective weighting method while this paper derives a combined subjective and objective weights of CRs as well.

Table 13. The comparative analysis of integrated QFD models.

\begin{tabular}{cccccc}
\hline & & Yazdani et al. & Liao and Kao & Wu et al. & This Paper \\
& & {$[6]$} & {$[54]$} & {$[3]$} & LZNs \\
\hline \multicolumn{2}{c}{ Information representation } & $\mathrm{CNs}$ & TFNs & HFNs & LZNe \\
Weights & Subjective weighting method & $\times$ & $\times$ & $\times$ & $\sqrt{ }$ \\
of TMs & Objective weighting method & $\times$ & $\times$ & $\sqrt{ }$ & $\sqrt{ }$ \\
Weights & Subjective weighting method & $\sqrt{ }$ & $\sqrt{ }$ & $\sqrt{ }$ & $\sqrt{ }$ \\
of CRs & Objective weighting method & $\times$ & $\times$ & $\times$ & $\sqrt{ }$ \\
\hline
\end{tabular}

Through the aforementioned comparisons, the advantages of proposed QFD models can be summarized as follows:

(1) Compared with crisp numbers and fuzzy numbers, LZNs can take fuzzy information and the reliability of information into considerations at the same time. Owing to powerful ability of LZNs' expressions, the proposed framework using LZNs can depict evaluation information perfectly.

(2) It is inadvisable that only adopting objective method to obtain weights of TMs. Because some data is be hard to obtain and quantify. The QFD experts have discrepant professional backgrounds and areas, the subjective preferences to the importance degree of expert TMs should also be thought of. With regard to the weights of CRs, it may cause large deviation when only subjective weighting method is employed. Therefore, the QFD model with integrated subjective and objective weights of CRs may be more reasonable.

(3) Compared with other MCDM method using LZNs, the proposed method only requires comparing engineering characteristics with PIS and NIS and avoids the problem: with the dimension increased, the calculated quantity rapidly does.

\section{Conclusions}

Since LZNs can deal with the uncertain and unreliable information well which exists in actual situations commonly, it is imperative to investigate the QFD framework utilizing LZNs. In this study, at first place, the weights of team members are identified by G1 method and improved MC method, respectively. Then, SWARA and SD methods are put forward to derive the subjective and objective weights of customer requirements. At this point, the combined weights of experts and customer requirements are determined. Next, the extended TOPSIS is proposed to aggregate the correlation between customer requirements and engineering characteristics. Finally, a case of logistics service provider is studied by the proposed QFD model to verify the efficiency and applicability of it. Moreover, a sensitivity analysis of LSFs is conducted to prove the robustness of our model. A comparison with the methods under LZN environment, and comparative analysis are conducted, the results indict the proposed QFD model has reliability. The way to determine the weights of CRs is a combined subjective and objective method, and the proposed method is more likely to be applied in real-life cases.

There are three main contributions in this paper. First, this paper develops an improved MC method which takes both positive and negative ideal assessment into account. Second, the novel QFD model is proposed by using LZNs and considering the combined weights of experts and customer requirements. Because LZNs can take fuzzy information and the reliability of information into considerations simultaneously, the proposed method can depict evaluation information more flexible and precisely. Third, the proposed QFD framework is utilized to discover the most significant engineering characteristics, which helps the logistics service providers to enhance their services. Compared with other MCDM method using LZNs, it only requires comparing engineering characteristics with PIS and NIS, which have fewer calculated quantities. 
In the future, researches can be made on these aspects. First of all, the interactive relationships among customer requirements could be paid attention to in the stage of weights determination and information fusion. Subsequently, both qualitative and quantitative data can be considered in the meantime to strengthen the completeness of information expression. Ultimately, the proposed QFD can be applied to improve operational services or product design, such as medical services [55], industrial wastewater management [56], and energy selection [57].

Author Contributions: C.S. and J.-Q.W. developed methodology and provided the original draft preparation. J.-Q.W. and J.-B.L. analyzed the data. All authors have read and agreed to the published version of the manuscript.

Funding: This work is supported by the National Natural Science Foundation of China (Grant No. 71871228).

Conflicts of Interest: The authors declare that there is no conflict of interest regarding the publication of this paper.

\section{References}

1. Akao, Y. New product development and quality assurance-quality deployment system. Stand. Qual. Control $1972,25,7-14$.

2. Osiro, L.; Lima-Junior, F.R.; Carpinetti, L.C.R. A group decision model based on quality function deployment and hesitant fuzzy for selecting supply chain sustainability metrics. J. Clean. Prod. 2018, 183, 964-978. [CrossRef]

3. Wu, S.-M.; Liu, H.-C.; Wang, L.-E. Hesitant fuzzy integrated MCDM approach for quality function deployment: A case study in electric vehicle. Int. J. Prod. Res. 2017, 55, 4436-4449. [CrossRef]

4. Dincer, H.; Yüksel, S.; Martinez, L. Balanced scorecard-based Analysis about European Energy Investment Policies: A hybrid hesitant fuzzy decision-making approach with Quality Function Deployment. Expert Syst. Appl. 2019, 115, 152-171. [CrossRef]

5. Onar, S.Ç.; Büyüközkan, G.; Öztayşi, B.; Kahraman, C. A new hesitant fuzzy QFD approach: An application to computer workstation selection. Appl. Soft Comput. 2016, 46, 1-16. [CrossRef]

6. Yazdani, M.; Chatterjee, P.; Zavadskas, E.K.; Zolfani, S.H. Integrated QFD-MCDM framework for green supplier selection. J. Clean. Prod. 2017, 142, 3728-3740. [CrossRef]

7. Dolgun, L.E.; Köksal, G. Effective use of quality function deployment and Kansei engineering for product planning with sensory customer requirements: A plain yogurt case. Qual. Eng. 2018, 30, 569-582. [CrossRef]

8. Yazdani, M.; Kahraman, C.; Zarate, P.; Onar, S.C. A fuzzy multi attribute decision framework with integration of QFD and grey relational analysis. Expert Syst. Appl. 2019, 115, 474-485. [CrossRef]

9. Chowdhury, M.M.H.; Quaddus, M.A. A multiple objective optimization based QFD approach for efficient resilient strategies to mitigate supply chain vulnerabilities: The case of garment industry of Bangladesh. Omega 2015, 57, 5-21. [CrossRef]

10. Jia, W.; Liu, Z.; Lin, Z.; Qiu, C.; Tan, J. Quantification for the importance degree of engineering characteristics with a multi-level hierarchical structure in QFD. Int. J. Prod. Res. 2016, 54, 1627-1649. [CrossRef]

11. Song, W.; Ming, X.; Han, Y. Prioritising technical attributes in QFD under vague environment: A rough-grey relational analysis approach. Int. J. Prod. Res. 2014, 52, 5528-5545. [CrossRef]

12. Zadeh, L.A. A note on Z-numbers. Inf. Sci. 2011, 181, 2923-2932. [CrossRef]

13. Qiao, D.; Shen, K.-W.; Wang, J.-Q.; Wang, T.-L. Multi-criteria PROMETHEE method based on possibility degree with Z-numbers under uncertain linguistic environment. J. Ambient Intell. Humaniz. Comput. 2019, 1-15. [CrossRef]

14. Shen, K.-W.; Wang, X.-K.; Qiao, D.; Wang, J.-Q. Extended Z-MABAC method based on regret theory and directed distance for regional circular economy development program selection with Z-information. IEEE Trans. Fuzzy Syst. 2019. [CrossRef]

15. Qiao, D.; Wang, X.-K.; Wang, J.-Q.; Chen, K. Cross Entropy for Discrete Z-numbers and Its Application in Multi-Criteria Decision-Making. Int. J. Fuzzy Syst. 2019, 21, 1786-1800. [CrossRef]

16. Wang, J-Q.; Cao, Y.-X.; Zhang, H.-Y. Multi-criteria decision-making method based on distance measure and Choquet integral for linguistic Z-numbers. Cogn. Comput. 2017, 9, 827-842. [CrossRef]

17. Huang, J.; Xu, D.-H.; Liu, H.-C.; Song, M.-S. A New Model for Failure Mode and Effect Analysis Integrating Linguistic Z-numbers and Projection Method. IEEE Trans. Fuzzy Syst. 2019. [CrossRef] 
18. Xu, F.; Liu, J.; Lin, S.; Yuan, J. A VIKOR-based approach for assessing the service performance of electric vehicle sharing programs: A case study in Beijing. J. Clean. Prod. 2017, 148, 254-267. [CrossRef]

19. Wu, X.; Liao, H. A consensus-based probabilistic linguistic gained and lost dominance score method. Eur. J. Oper. Res. 2019, 272, 1017-1027. [CrossRef]

20. Zavadskas, E.K.; Bausys, R.; Juodagalviene, B.; Garnyte-Sapranaviciene, I. Model for residential house element and material selection by neutrosophic MULTIMOORA method. Eng. Appl. Artif. Intell. 2017, 64, 315-324. [CrossRef]

21. Liu, H.-C.; You, J.-X.; Chen, S.; Chen, Y.-Z. An integrated failure mode and effect analysis approach for accurate risk assessment under uncertainty. IIE Trans. 2016, 48, 1027-1042. [CrossRef]

22. Saaty, T.L.; Kearns, K.P. The Analytic Hierarchy Process; RWS: Cologne, Germany, 1985.

23. Hwang, C.-L.; Yoon, K. Multiple Attribute Decision Making: Methods and Applications a State-of-the-Art Survey; Springer Science \& Business Media: Berlin, Germany, 1981; Volume 186.

24. Roy, B. Classement et choix en présence de points de vue multiples. Rev. Fr. D'informatique Rech. Oper. 1968, 2, 57-75. [CrossRef]

25. Opricovic, S.; Tzeng, G.-H. Compromise solution by MCDM methods: A comparative analysis of VIKOR and TOPSIS. Eur. J. Oper. Res. 2004, 156, 445-455. [CrossRef]

26. Mareschal, B.; Brans, J.P.; Vincke, P. PROMETHEE: A New Family of Outranking Methods in Multicriteria Analysis; ULB-Universite Libre de Bruxelles: Bruxelles, Belgium, 1984.

27. Julong, D. Introduction to grey system theory. J. Grey Syst. 1989, 1, 1-24.

28. Rezaei, J. Best-worst multi-criteria decision-making method. Omega 2015, 53, 49-57. [CrossRef]

29. Hsu, C.-H.; Chang, A.-Y.; Luo, W. Identifying key performance factors for sustainability development of SMEs-integrating QFD and fuzzy MADM methods. J. Clean. Prod. 2017, 161, 629-645. [CrossRef]

30. Zaim, S.; Sevkli, M.; Camgöz-Akdağ, H.; Demirel, O.F.; Yayla, A.Y.; Delen, D. Use of ANP weighted crisp and fuzzy QFD for product development. Expert Syst. Appl. 2014, 41, 4464-4474. [CrossRef]

31. Abdel-Basset, M.; Manogaran, G.; Mohamed, M.; Chilamkurti, N. Three-way decisions based on neutrosophic sets and AHP-QFD framework for supplier selection problem. Future Gener. Comput. Syst. 2018, 89, 19-30. [CrossRef]

32. Wu, X.; Nie, L.; Xu, M. Robust fuzzy quality function deployment based on the mean-end-chain concept: Service station evaluation problem for rail catering services. Eur. J. Oper. Res. 2017, 263, 974-995. [CrossRef]

33. Abdel-Basset, M.; Mohamed, R.; Zaied, A.E.-N.H.; Smarandache, F. A hybrid plithogenic decision-making approach with quality function deployment for selecting supply chain sustainability metrics. Symmetry 2019, 11, 903. [CrossRef]

34. Yang, Q.; Chin, K.-S.; Li, Y.-L. A quality function deployment-based framework for the risk management of hazardous material transportation process. J. Loss Prev. Process Ind. 2018, 52, 81-92. [CrossRef]

35. Tian, C.; Peng, J.-J.; Zhang, W.-Y.; Zhang, S.; Wang, J.-Q. Tourism environmental impact assessment based on improved AHP and picture fuzzy PROMETHEE II methods. Technol. Econ. Dev. Econ. 2019, 1-24. [CrossRef]

36. Yu, S.M.; Wang, J.; Wang, J.Q. An extended TODIM approach with intuitionistic linguistic numbers. Int. Trans. Oper. Res. 2018, 25, 781-805. [CrossRef]

37. Wang, J.Q.; Han, Z.Q.; Zhang, H.Y. Multi-criteria Group Decision-Making Method Based on Intuitionistic Interval Fuzzy Information. Group Decis. Negot. 2014, 23, 715-733. [CrossRef]

38. Wang, L.; Wang, X.-K.; Peng, J.-J.; Wang, J.-Q. The differences in hotel selection among various types of travellers: A comparative analysis with a useful bounded rationality behavioural decision support model. Tour. Manag. 2020, 76, 103961. [CrossRef]

39. Herrera, F.; Herrera-Viedma, E.; Verdegay, J.L. A model of consensus in group decision making under linguistic assessments. Fuzzy Sets Syst. 1996, 78, 73-87. [CrossRef]

40. Zhang, H.-Y.; Peng, H.-G.; Wang, J.; Wang, J.-Q. An extended outranking approach for multi-criteria decision-making problems with linguistic intuitionistic fuzzy numbers. Appl. Soft Comput. 2017, 59, 462-474. [CrossRef]

41. Bao, G.-Y.; Lian, X.-L.; He, M.; Wang, L.-L. Improved two-tuple linguistic representation model based on new linguistic evaluation scale. Control Decis. 2010, 25, 780-784.

42. Kahneman, D.; Tversky, A. Prospect theory: An analysis of decision under risk. Econom. J. Econom. Soc. 1979, 47, 263-291. [CrossRef] 
43. Versaci, M.; La Foresta, F.; Morabito, F.C.; Angiulli, G. A fuzzy divergence approach for solving electrostatic identification problems for NDT applications. Int. J. Appl. Electromagn. Mech. 2018, 57, 133-146. [CrossRef]

44. Versaci, M. Fuzzy approach and Eddy currents NDT/NDE devices in industrial applications. Electron. Lett. 2016, 52, 943-945. [CrossRef]

45. Wang, L.; Zhang, H.; Wang, J.; Wu, G. Picture fuzzy multi-criteria group decision making method to hotel building energy efficiency retrofit project selection. Rairo Oper. Res. 2018. [CrossRef]

46. Ruan, C.; Yang, J. Software quality evaluation model based on weighted mutation rate correction incompletion G1 combination weights. Math. Probl. Eng. 2014, 2014. [CrossRef]

47. Zhang, X.; Xu, Z. Soft computing based on maximizing consensus and fuzzy TOPSIS approach to interval-valued intuitionistic fuzzy group decision making. Appl. Soft Comput. 2015, 26, 42-56. [CrossRef]

48. Zolfani, S.H.; Chatterjee, P. Comparative evaluation of sustainable design based on Step-wise Weight Assessment Ratio Analysis (SWARA) and best worst method (BWM) methods: A perspective on household furnishing materials. Symmetry 2019, 11, 74. [CrossRef]

49. Shahsavar, S.; Rad, A.J.; Afzal, P.; Nezafati, N.; Aghdam, M.A. Prospecting for polymetallic mineralization using step-wise weight assessment ratio analysis (SWARA) and fractal modeling in Aghkand Area, NW Iran. Arab. J. Geosci. 2019, 12, 248. [CrossRef]

50. Nakhaei, J.; Bitarafan, M.; Lale Arefi, S.; Kapliński, O. Model for rapid assessment of vulnerability of office buildings to blast using SWARA and SMART methods (a case study of swiss re tower). J. Civ. Eng. Manag. 2016, 22, 831-843. [CrossRef]

51. Selvachandran, G.; Quek, S.; Smarandache, F.; Broumi, S. An extended technique for order preference by similarity to an ideal solution (TOPSIS) with maximizing deviation method based on integrated weight measure for single-valued neutrosophic sets. Symmetry 2018, 10, 236. [CrossRef]

52. Hu, J.; Yang, Y.; Zhang, X.; Chen, X. Similarity and entropy measures for hesitant fuzzy sets. Int. Trans. Oper. Res. 2018, 25, 857-886. [CrossRef]

53. Oláh, J.; Karmazin, G.; Pető, K.; Popp, J. Information technology developments of logistics service providers in Hungary. Int. J. Logist. Res. Appl. 2018, 21, 332-344. [CrossRef]

54. Liao, C.-N.; Kao, H.-P. An evaluation approach to logistics service using fuzzy theory, quality function development and goal programming. Comput. Ind. Eng. 2014, 68, 54-64. [CrossRef]

55. Hu, J.; Zhang, X.; Yang, Y.; Liu, Y.; Chen, X. New doctors ranking system based on VIKOR method. Int. Trans. Oper. Res. 2020, 27, 1236-1261. [CrossRef]

56. Shen, K.-W.; Li, L.; Wang, J.-Q. Circular economy model for recycling waste resources under government participation: A case study in industrial waste water circulation in China. Technol. Econ. Dev. Econ. 2020, 26, 21-47. [CrossRef]

57. Peng, H.; Wang, J.; Zhang, H. Multi-criteria outranking method based on probability distribution with probabilistic linguistic information. Comput. Ind. Eng. 2020, 106318. [CrossRef] 